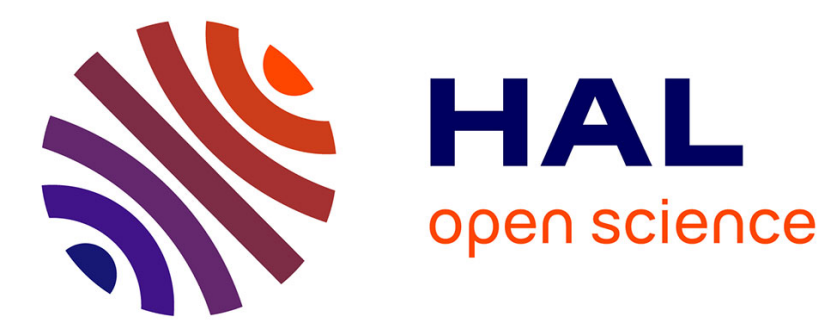

\title{
Dedicated linear - Voce model and its application in investigating temperature and strain rate effects on sheet formability of aluminum alloys
}

Cunsheng Zhang, Xingrong Chu, Dominique Guines, Lionel Leotoing, Jie Ding, Guoqun Zhao

\section{To cite this version:}

Cunsheng Zhang, Xingrong Chu, Dominique Guines, Lionel Leotoing, Jie Ding, et al.. Dedicated linear - Voce model and its application in investigating temperature and strain rate effects on sheet formability of aluminum alloys. Materials \& Design, 2015, 67, pp.522-530. 10.1016/j.matdes.2014.10.074 . hal-01151211

\author{
HAL Id: hal-01151211 \\ https://hal.science/hal-01151211
}

Submitted on 12 May 2015

HAL is a multi-disciplinary open access archive for the deposit and dissemination of scientific research documents, whether they are published or not. The documents may come from teaching and research institutions in France or abroad, or from public or private research centers.
L'archive ouverte pluridisciplinaire HAL, est destinée au dépôt et à la diffusion de documents scientifiques de niveau recherche, publiés ou non, émanant des établissements d'enseignement et de recherche français ou étrangers, des laboratoires publics ou privés. 
Dedicated linear - Voce model and its application in investigating temperature and strain rate effects on sheet formability of aluminum alloys

Cunsheng Zhang ${ }^{1 *}$, Xingrong $\mathrm{Chu}^{2}$, Dominique Guines ${ }^{3}$, Lionel Leotoing ${ }^{3}$, Jie Ding $^{1}$, Guoqun Zhao ${ }^{1}$

${ }^{1}$ Key Laboratory for Liquid-Solid Structural Evolution and Processing of Materials (Ministry of Education), Shandong University, Jinan 250061, P.R.China

${ }^{2}$ School of Mechanical, Electrical and Information Engineering, Shandong University, Weihai 264209, P.R.China

${ }^{3}$ Université Européenne de Bretagne, France, INSA-LGCGM - EA 3913 20, avenue des Buttes de Coësmes 35043 RENNES Cédex

${ }^{*}$ Corresponding author. Tel.: +86(0) 531-81696555

E-mail address: zhangcs@sdu.edu.cn

\section{Abstract}

This paper proposes a method to investigate the effects of temperature and strain rate on the forming limit curves (FLCs) by combining a modified Voce constitutive model (Lin-Voce model) with the numerical simulation of Marciniak test. The tensile tests are firstly carried out at different forming temperatures $\left(20,230\right.$ and $\left.290^{\circ} \mathrm{C}\right)$ and strain rates $\left(2.5,120\right.$ and $\left.150 \mathrm{~s}^{-1}\right)$ for AA5086 sheet. A modified Voce constitutive model (named Lin-Voce model) is proposed to describe the deformation behavior of AA5086 and its material parameters are identified by inverse analysis technique. Then, the proposed constitutive model is verified by comparing numerical and experimental results obtained by tensile tests and Marciniak test, respectively. Finally, the numerical simulation of Marciniak test is carried out at different temperatures $\left(100,200\right.$ and $\left.300^{\circ} \mathrm{C}\right)$ and strain rates $\left(2.5,120\right.$ and $\left.150 \mathrm{~s}^{-1}\right)$, and the effects of temperature and strain rate on the FLCs of AA5086 are investigated and discussed.

Keywords: Inverse analysis; Lin-Voce constitutive model; Marciniak test; Forming limit curves 


\section{Introduction}

With an increasingly severe effect of global warming, automotive vehicles with low energy consumption, low pollution and high fuel economy are becoming more and more popular. Lightweight has become the development theme of world auto-industry. Due to its small density and high specific strength, aluminum alloys have attracted lots of attentions. However, the low formability at room temperature greatly limits their application [1-2].

To improve aluminum sheet formability, warm forming process has become a promising technique. In recent years, scholars have done much work on sheet warm formability by different experimental methods [3-10]. Naka and Yoshida [3] investigated forming speed and temperature effects on the deep drawability for AA5083-O with cylindrical deep drawing tests at different forming speeds $(0.2-500 \mathrm{~mm} / \mathrm{min})$ and die temperatures $\left(27-180^{\circ} \mathrm{C}\right)$. It was found that the limit drawing ratio increased with the increasing die temperature and decreased with the increasing forming speed. Li and Ghosh [4] investigated the tensile deformation behavior of AA5754, AA5182 and AA6111-T4 under different temperatures (200-350 $\left.{ }^{\circ} \mathrm{C}\right)$ and strain rates $\left(0.015-1.5 \mathrm{~s}^{-1}\right)$. The total elongation was found to increase with increasing temperature and to decrease with increasing strain rate. In another work of $\mathrm{Li}$ and Ghosh [5], the formability of the above three aluminum alloys was studied by forming rectangular designed parts at different temperatures from 200 to $350^{\circ} \mathrm{C}$ with a strain rate of $1 \mathrm{~s}^{-1}$. A significantly positive effect of forming temperature on the sheet drawing formability was found and this effect varied for different materials. Palumbo and Tricarico [6] investigated AA5754-O formability based on a warm deep drawing equipment. A remarkable rise of about $44 \%$ in limit drawing ratio compared to that at ambient temperature was obtained at the punch speed 
of $1 \mathrm{~mm} / \mathrm{min}$ and at the temperature of $110^{\circ} \mathrm{C}$ in the blank center. Mahabunphachai and Koç [7] found that the formability of AA5052 and AA6061 increased with temperature (from room temperature to $\left.300^{\circ} \mathrm{C}\right)$ and decreased with strain rate $\left(0.0013\right.$ and $\left.0.013 \mathrm{~s}^{-1}\right)$ by bulge tests. Wang et al. [8] also found that both temperature and punch speed had a strong influence on the formability of AA2024 by a cup punch test. Fan et al. [9] investigated the deformation behavior of $5 \mathrm{~A} 06$ for rapid gas forming at elevated temperatures $\left(325-500^{\circ} \mathrm{C}\right)$, and it was found that the sheet formability was improved by the increasing temperature, duration time and gas pressure. The formability of AA7075 was studied by Wang et al. [10] through the limiting drawing ratio test and the limit dome height test. The results showed that the sheet formability could be significantly improved when the blank was heated to $140-220^{\circ} \mathrm{C}$ and it began to decrease at the temperature over $260^{\circ} \mathrm{C}$.

The forming limit curve (FLC), developed by Keeler and Backofen [11] in the 1960s, is widely used to evaluate the sheet metal formability. Based on the previous literatures, the aluminum alloy is very sensitive to strain rate at warm forming temperatures, and different mechanical properties can be observed at high and quasi-static strain rates [12-14]. Naka et al. [15] investigated experimentally forming speed and temperature effects on the FLCs of AA5083-O by performing stretch-forming tests at different forming speeds $(0.2-200 \mathrm{~mm} / \mathrm{min})$ and temperatures $\left(20-300^{\circ} \mathrm{C}\right)$. It was shown that the FLCs increased drastically with the decreasing test speed for any strain path at temperatures ranging from 150 to $300^{\circ} \mathrm{C}$, while at room temperature the FLCs was not sensitive to forming speed. Chu et al. [16] obtained the FLCs of AA5086 under different temperatures $\left(20,150\right.$ and $\left.200^{\circ} \mathrm{C}\right)$ and strain rates $(0.02,0.2$ and $2 \mathrm{~s}^{-1}$ ) by Marciniak test and Marciniak-Kuczinsky (M-K) model. It was found that both 
temperature and strain rate have an important influence on the FLCs of AA5086. Khan and Baig [17] studied the effects of temperature $\left(20-300^{\circ} \mathrm{C}\right)$ and strain rate $\left(10^{-4}\right.$ to $\left.1 \mathrm{~s}^{-1}\right)$ for AA5182-O formability through M-K model, KHL constitutive equation and Barlat YLD96 yield function. It was found that strain rate effect varied at different temperatures.

Due to the complexity and difficulty in carrying out the physical Marciniak test under high strain rates and at elevated temperatures, current studies regarding the effect of strain rate on FLCs are mostly based on M-K theory, but only a small range of strain rate was covered in these works, so current research about temperature and strain rate effects on the FLCs of aluminum alloys is still relatively lacking. Therefore, the purpose of this work is to investigate temperature and strain rate effects on FLCs of aluminum alloys by combining a proposed Lin-Voce constitutive model and the simulation of Marciniak test. Due to the lack of uniform standard about dynamic tensile test, a lab-design dynamic tensile device is used. The tensile tests are carried out under different temperature and strain rate. Material parameters in Lin-Voce model are indentified through inverse analysis technique. To verify the proposed constitutive model, Marciniak tests at room temperature with a strain rate of $2.5 \mathrm{~s}^{-1}$ are carried out. Finally, the FLCs of AA5086 under different strain rates $\left(2.5,120\right.$ and $\left.150 \mathrm{~s}^{-1}\right)$ and temperatures $\left(100,200\right.$ and $\left.300^{\circ} \mathrm{C}\right)$ are predicted and the influences of temperature and strain rate on the FLCs of AA5086 are discussed.

\section{Uniaxial tensile test}

In this section, the tensile tests at different temperatures $\left(20,230\right.$ and $\left.290^{\circ} \mathrm{C}\right)$ and strain rates $\left(2.5,120\right.$ and $\left.150 \mathrm{~s}^{-1}\right)$ are carried out for AA5086. Limit strains under all forming conditions are obtained by the digital image correlation (DIC) technique. 


\subsection{Experimental specimen and apparatus}

To ensure the necking occur in the center, the tensile specimen used in this work is designed with a notch, as shown in Fig 1 . The sheet thickness is $2 \mathrm{~mm}$. To facilitate the digital image correlation analysis, all specimens are sprayed with black dots on a uniform white background to produce a random distribution of speckle pattern. A new grip system (Fig. 1) is designed to allow the specimen to have a predetermined run under high strain rates conditions. Specimens are heated by an induction heating system.

\subsection{Analysis of experimental data}

Figure 2 shows the force vs time curves at different temperatures and strain rates. The thermal softening effect can be clearly observed on these curves. Deformation resistance decreases with the increasing temperature at a same strain rate. At $2.5 \mathrm{~s}^{-1}$, the maximum tensile force is decreased by $37.22 \%$ when the temperature increases from $20^{\circ} \mathrm{C}$ to $290^{\circ} \mathrm{C}$. Figure 3 shows the influence of strain rate on force vs displacement curves at a given temperature. It can be observed that AA5086 is not sensitive to strain rate at $20^{\circ} \mathrm{C}$. When strain rate increases from 2.5 to $150 \mathrm{~s}^{-1}$, the force vs displacement curves have no obvious change. However, the material becomes very sensitive to strain rate at $290^{\circ} \mathrm{C}$. The maximum force is increased by $11.98 \%$ when strain rates increases from 2.5 to $150 \mathrm{~s}^{-1}$. From the above comparison, it can be observed that strain rate has an important influence on the flow behavior of AA5086 at elevated temperatures. In order to accurately describe its warm deformation behavior, it is essential to take strain rate into account. 


\subsection{Strain calculation}

A high-speed camera and DIC technique is used to analyze the forming process of the specimen. Detailed description of strain calculation process can be seen in the author's previous work [18]. A failure criterion widely used for the M-K model is chosen during the strain calculation process: when the ratio of average equivalent plastic strain increments in the localized and non-localized zones reaches 7, localized necking is assumed to occur [19-20]. According to this method, limit strains at different temperatures and strain rates are obtained. In the test, three specimens are repeated for each experimental condition, and the average major strains are obtained, as shown in Fig. 4.

Comparing the limit strains obtained under different forming conditions, it can be observed that the AA5086 formability is clearly affected by both temperature and strain rate. Temperature plays a prominent role at low strain rate, and the sheet formability is enhanced greatly at elevated temperatures. At $2.5 \mathrm{~s}^{-1}$, the limit strain rises by $25.47 \%$ when temperature increases from 20 to $290^{\circ} \mathrm{C}$. Under high strain rates $\left(120\right.$ and $\left.150 \mathrm{~s}^{-1}\right)$, due to the interaction of temperature and strain rate, the limit strain no longer increases monotonically with the rising temperature. Instead, it shows a declining trend, and the limit strain becomes relatively low at $230^{\circ} \mathrm{C}$. Compared to that at room temperature, the limit strain at $230^{\circ} \mathrm{C}$ under 120 and $150 \mathrm{~s}^{-1}$ decreases by $19.6 \%$ and $28 \%$, respectively.

As well as the deformation behavior at room temperature, the AA5086 limit strain is insensitive to strain rate neither. As temperature increases, AA5086 turns to be sensitive to strain rate, whose negative effect becomes increasingly prominent. The limit strains of AA5086 at high strain rates are clearly lower than that at $2.5 \mathrm{~s}^{-1}$. A $36 \%$ reduction in major 
strain is observed when the strain rate increases from 2.5 to $120 \mathrm{~s}^{-1}$ at $290^{\circ} \mathrm{C}$. However, further comparison of limit strains at 120 and $150 \mathrm{~s}^{-1}$ exhibits an interesting phenomenon that the limit strain does not decrease monotonically with increasing strain rate at elevated temperatures. At 230 and $290^{\circ} \mathrm{C}$, the limit strains of AA5086 at $150 \mathrm{~s}^{-1}$ are increased by $18.71 \%$ and $4.73 \%$ than those at $120 \mathrm{~s}^{-1}$, respectively. The abnormal phenomenon can be explained as follows: the increase of limit strain may be due to local strain hardening and rapid changes in dislocation structure during high-speed deformation, which delays the occurrence of necking and improves the sheet formability. The identical phenomenon is also observed for CQ steel [21], DP600 and AA7003 [22] and Magnesium alloys [23-24]. To verify the observation in this work, further examinations on microstructure evolution should be carried out.

\section{Construction and identification of a modified constitutive model}

In this section, a modified Voce constitutive model coupling temperature and strain rate is proposed to describe the forming behavior of AA5086 under different forming conditions and its material parameters are identified by the inverse analysis technique.

\subsection{Parameter identification based on inverse analysis}

Currently, material parameters in a constitutive model are mostly determined by the regression analysis, where the deformation in a tensile specimen is assumed to be uniform before the occurrence of the necking. Although for a regular tensile specimen, its cross-section geometry varies during the test. Moreover, the heat caused by plastic deformation during forming process, which plays an important role at dynamic forming conditions, could not be considered with the traditional method, so its calculation accuracy is relatively low. Especially, for the irregular cross-section of the specimen used in this work, it 
is impossible to identify material parameters of the constitutive models by the regression analysis. Thus, the inverse analysis is adopted in this work.

The basic concept of an inverse analysis for parameter identification is to find out a set of unknown material parameters by continuous iterations based on numerical simulation and experimental data. To obtain these parameters, the following three elements should be considered:

(1) Experimental data as the input data (e.g., the measured force and time in this work);

(2) A numerical model of the physical experiment that provides the required output data (e.g., a FE tensile test model in this work);

(3) An optimization procedure which can analyze the discrepancy between numerical and experimental data, and update current values of the unknown parameters.

Principal of the optimization procedure by the inverse analysis is introduced by Diot et al. [25], as show in Fig. 5. The final material parameters $P$ are obtained when the cost function (E) between the prediction and the experimental values reaches the pre-defined critical value.

Based on the above optimization idea, a FE model of the tensile test is established, as shown in Fig. 6. Considering the symmetrical boundary conditions, only $1 / 8$ of the entire model is built. The influence of the tensile test machine's elastic on the determined parameters is also taken into account, which is described by a truss element in the FE model. By defining the specific heat, the thermal conductivity, the thermal expansion coefficient and the inelastic heat fraction in the FE model, the heat caused by plastic deformation during forming process is considered.

The error $\mathrm{E}_{\mathrm{r}}$ between the numerical and experiment data can be defined by: 


$$
E_{r}=\frac{\sum_{i=1}^{N}\left[F_{i}^{\mathrm{exp}}-F_{i}^{c a l}\right]^{2}}{\sum_{i=1}^{N}\left[F_{i}^{\exp }\right]^{2}}
$$

Where $F_{\mathrm{i}}^{\text {exp }}$ and $F_{\mathrm{i}}^{\text {cal }}$ denote the forces obtained by experiments and FE simulations at the $\mathrm{i}^{\text {th }}$ increment, respectively. $\mathrm{N}$ is the number of experimentally measured force points.

In this work, the software modeFRONTIER is used to integrate the optimization procedure, the inverse analysis and the FE model to identify material parameters in the constitutive model.

\subsection{Construction of constitutive law}

Voce hardening law is usually used to describe the rheological behaviors of the aluminum alloys which exhibit a saturation stress-strain state at high strain levels and at high temperatures [26-28]. In the previous work of the present authors [18], a modified Voce type hardening law was used to describe the strain hardening behavior of AA5086, where the strain hardening index $\mathrm{n}$ and the strain rate sensitivity index $\mathrm{m}$ are expressed as functions of the forming temperature (Eq.2). But there is much discrepancy between experimental and identified force-time curves.

$$
\bar{\sigma}=\sigma_{Y}+C_{1} \sqrt{1-\exp \left(-C_{2} \exp \left(C_{3} T\right) \bar{\varepsilon}\right)} \exp \left(C_{4} / T\right) \dot{\bar{\varepsilon}}^{m(\mathrm{~T})}
$$

where, $\bar{\sigma}$ is the flow stress, $\sigma_{Y}$ is the yield stress, $C_{1}, C_{2}, C_{3}$ and $C_{4}$ are material parameters.

In the work of Abedrabbo et al. [29], the strain rate sensitivity index m was fitted by a power exponent equation, and here $\mathrm{m}$ is expressed as $m(T)=C_{5} \exp \left(C_{6} T\right)$. Based on the inverse analysis introduced in section 3.1, the material parameters in Eq.2 are indentified for different temperatures at the strain rate of $2.5 \mathrm{~s}^{-1}$. Since the strain rate is relatively low and 
kept same, the influence of the strain rate is not taken into account, thus the strain rate sensitivity factor $\mathrm{m}$ is set to zero during the parameters identification. The identified results are shown in Table 1.

With the identified parameters, the values of $C_{1} \exp \left(C_{4} / T\right)$ at different temperatures are calculated. It is observed that there exists a linear relationship between $C_{1} \exp \left(C_{4} / T\right)$ and temperature (as shown in Fig.7). In addition, it is obtained from Table 1 that $C_{3}$ is very small, thus the value of $\exp \left(C_{3} T\right)$ is nearly to 1 . According to the above analysis, Lin-Voce constitutive model, in which the strain hardening has a linear relationship with temperature, is proposed, as expressed in Eq.3.

$$
\bar{\sigma}=\sigma_{Y}+\left(\mathrm{C}_{1}+\mathrm{C}_{2} \mathrm{~T}\right) \sqrt{1-\exp \left(-\mathrm{C}_{3} \bar{\varepsilon}\right)} \dot{\bar{\varepsilon}}^{C_{4} \exp \left(\mathrm{C}_{5} \mathrm{~T}\right)}
$$

where, $C_{1}$ and $C_{2}$ are the strain hardening coefficients, $C_{3}$ is the strain softening coefficient, $C_{4}$ and $C_{5}$ are the strain rate sensitivity coefficients.

\subsection{Optimization results}

In this work, the hypothesis that the yield strength depends only on temperature but not on strain rate is taken, which is also adopted in the work of Chu et al.[16] and Pedersen et al. [30]. Due to the irregular specimen's cross-section, the yield strength cannot be obtained by traditional methods. So in this paper, the yield strength is set as a variable and the material parameters in Lin-Voce constitutive model are identified by the inverse analysis based on experimental data, as listed in Table 2 and Table 3.

Figure 8 illustrates the experimental and identified force vs time curves at different forming conditions. From the figure, the identified curves have an excellent agreement with experimental ones at the strain rate of $2.5 \mathrm{~s}^{-1}$. Considering the measurement errors caused by 
the vibrations of the testing system at high strain rates, the little discrepancy between fitted and experimental curves is acceptable. The maximum error between experimental and fitted curves is only $2.656 \%$, as listed in Table 3 . It can be concluded that Lin-Voce constitutive model is suitable to describe the deformation behavior of AA5086 under different forming conditions.

\section{Experimental verification}

In order to validate Lin-Voce constitutive model, both the uniaxial tensile test and Marciniak test are carried out in this section.

\subsection{Verification by the uniaxial tensile test}

Lin-Voce constitutive model is implemented into FE model (Fig. 6) via ABAQUS UHARD subroutine. The experimental conditions in section 2 are copied during the FE simulation of the tensile test. Using the same necking criterion as in the experiments, the limit strains are obtained by a series of FE simulations, as shown in Fig.9.

From the comparison in Fig.9, it can be seen that numerical limit strains have a good agreement with experimental ones. The effects of temperature and strain rate on the limit strains predicted by FE simulations show the same tendency with experimental results, which verifies that Lin-Voce constitutive model can describe accurately the deformation behavior of AA5086 under different forming conditions. As mentioned in sub-section 2.3, the limit strain of AA5086 seems to be lowest at about $230^{\circ} \mathrm{C}$ under high strain rates $\left(120\right.$ and $\left.150 \mathrm{~s}^{-1}\right)$. In order to find out the relatively accurate temperature at which the negative effect of strain rate is the most significant under high strain rates, the tensile tests at other temperatures $(180,250$ 
and $260^{\circ} \mathrm{C}$ ) are also simulated, and the limit strains are obtained and listed in Table 4 . It is observed that the limit strain at $250^{\circ} \mathrm{C}$ is lower than those at $230^{\circ} \mathrm{C}$ and at $260^{\circ} \mathrm{C}$. Thus, it is concluded that the lowest limit strain of AA5086 occurs at $250^{\circ} \mathrm{C}$. Hence, while determining process parameters for AA5086 at elevated temperatures and at high strain rates, the temperature of about $250^{\circ} \mathrm{C}$ must be avoided.

\subsection{Verification by Marciniak test}

In this sub-section, experimental Marciniak test is carried out under a strain rate of $2.5 \mathrm{~s}^{-1}$ at room temperature, and the deformation analysis is carried out by CORRELA. To verify Lin-Voce constitutive model, the model is implemented into FE-Marciniak test model under identical forming conditions.

\subsubsection{Preparation and results analysis of Marciniak test}

Marciniak test setup and its schematic illustration are shown in Fig. 10. To facilitate capturing the deformation process of the blank, a reverse structure with a bell jar is designed. An optic mirror is used to reflect forming process to the high speed camera.

To cover more strain paths, 13 specimens with different widths are used (Fig. 11). The specimens are designed with non-uniform thicknesses: the central part has a thickness of 0.8 $\mathrm{mm}$, while the adjacent and the clamping parts are in 1.5 and $2.0 \mathrm{~mm}$, respectively. Thus, the plastic localization is triggered on the center part of the blank to facilitate capturing the deformation and to eliminate the effect of friction on forming limits.

\subsubsection{Construction of the FE-Marciniak model}

Corresponding to the experimental setup in Fig. 10, the FE-Marciniak model consists in 
three parts: a rigid cylindrical punch with a flat bottom, a rigid die and a deformable specimen. Due to the symmetrical boundary conditions, only a quarter part of the geometrical model is considered, as shown in Fig. 12. To copy the lubricant condition in the experiments, the friction coefficient of Coulomb's law between the central section of blank and punch in the FE model is set to 0. Lin-Voce constitutive model is implemented into the FE model (Fig. 6) via ABAQUS UHARD subroutine. To compare with experimental results, specimen shapes, forming conditions and necking criterion used in the FE model are identical to those in the physical Marciniak test.

Figure 13 shows the FLCs obtained by the physical Marciniak test and FE-Marciniak test at the strain rate of $2.5 \mathrm{~s}^{-1}$ at room temperature. A great consistency can be observed, which also proves that Lin-Voce constitutive model is suitable for describing deformation behavior of AA5086 in a large range of strains.

\section{Prediction of the effects of temperature and strain rate on the FLCs of AA5086}

Considering the difficulty in carrying out Marciniak test under high strain rates and at elevated temperatures, the FE-Marciniak model combined with the Lin-Voce constitutive model is used to simulate the experimental process in this section at different temperatures $\left(100,200\right.$ and $\left.300^{\circ} \mathrm{C}\right)$ and at different strain rates $\left(2.5,120\right.$ and $\left.150 \mathrm{~s}^{-1}\right)$. Then the effects of temperature and strain rate on the FLCs of AA5086 are discussed.

To obtain the yield strengths at other temperatures, based on Rusinek's work [31], a modified equation (Eq.4) is proposed to describe the evolution of yield strength in this paper. Figure 14 shows the fitting result with the yield strengths obtained at 20,230 and $290^{\circ} \mathrm{C}$, and the corresponding fitting parameters are listed in Table 5. It can be seen that Eq.4 gives a good 
description for the evolution of yield strength in the test temperature range. With this equation, yield strengths of AA5086 at 100, 200 and $300^{\circ} \mathrm{C}$ are obtained, as described with solid dots in Fig.14.

$$
f(\sigma, \mathrm{T})=\left[1-k_{1} \frac{T-T_{0}}{T_{m}-T} \exp \left(k_{2}\left(1-\frac{T_{m}-T}{T-T_{0}}\right)\right)\right] \sigma_{0}
$$

where $\sigma$ is the yield strength at temperature $T, \sigma_{0}$ is the yield strength at room temperature, $T_{m}$ is the melting temperature, which is $900 \mathrm{~K}$ for aluminum alloys, $T_{0}$ is the reference temperature, $k_{1}$ and $k_{2}$ are the fitting parameters.

By combining the obtained yield strengths and the Lin-Voce model, the FLCs of AA5086 at different strain rates and temperatures are obtained by the corresponding FE simulation, as shown in Fig. 15.

It can be observed from Fig. 15 that forming temperature has a significant influence on the FLCs of AA5086. The limit strain increases with the rising temperature at $2.5 \mathrm{~s}^{-1}$. Compared to those at room temperature, the limit strains at $300^{\circ} \mathrm{C}$ under the uniaxial tension, the plane strain and the equi-biaxial stretching are increased by $51.3 \%, 92.9 \%$ and $116.59 \%$, respectively. However, under high strain rates $\left(120\right.$ and $\left.150 \mathrm{~s}^{-1}\right)$, the negative effect of strain rate plays a prominent role, which offsets the positive effect of temperature on sheet formability, resulting that the FLC at $200^{\circ} \mathrm{C}$ is lower than that at room temperature. While with the increasing temperature, the positive effect of temperature on the sheet formability gradually compensates the negative effect of strain rate, consequently, the FLC at $300^{\circ} \mathrm{C}$ is close to that at room temperature, which is similar to the observation obtained by the tensile tests.

Figure 16 shows the FLCs at 2.5 and $150 \mathrm{~s}^{-1}$ at different temperatures. From the figure, 
FLC at the high strain rate is always lower than that with the low strain rate at a given temperature, indicating that strain rate has a negative effect on sheet formability. At $200^{\circ} \mathrm{C}$, the limit strains at $150 \mathrm{~s}^{-1}$ under the uniaxial tension, the plane strain and the equi-biaxial stretching are decreased by $36.1 \%, 45.2 \%$ and $50.2 \%$ compared to that at room temperature.

Thus, for aluminum alloys, the warm formability depends on the offsetting interaction of temperature and strain rate. At low temperatures, the positive effect of temperature could not compensate the negative effect of strain rate, as a result, the formability under high strain rates at $200^{\circ} \mathrm{C}$ becomes lower than that at room temperature. As the temperature increases, the two interacting effects arrive a balance, thus the sheet formability under high strain rates at $300^{\circ} \mathrm{C}$ is close to that at room temperature.

In order to investigate the effects of strain rates on the sheet formability of AA5086 above $300^{\circ} \mathrm{C}$, FLCs at 120 and $150 \mathrm{~s}^{-1}$ under $350^{\circ} \mathrm{C}$ are obtained by the FE-Marciniak test. It can be found that the formability at $350^{\circ} \mathrm{C}$ is improved compared to that at room temperature (Table 6). The forming limits under the uniaxial tension, the plane strain and the equi-biaxial stretching are increased by $13.51 \%, 31.82 \%$ and $23.68 \%$, respectively. Therefore, it can be concluded that the blank must be heated to a certain temperature above $300^{\circ} \mathrm{C}$ if one wants to improve the formability of AA5086 under high strain rates conditions.

\section{Conclusion}

Lin-Voce constitutive model, in which strain hardening shows a linear relationship with temperature, is proposed and identified to describe the rheological behavior of AA5086 in this work. With the proposed constitutive model, the dynamic tensile tests and Marciniak test are simulated at different temperatures and strain rates to investigate the effects of temperature 
and strain rate on sheet formability of AA5086. The conclusions are drawn as follows:

(1) According to the dynamic tensile tests at elevated temperatures, the sheet formability of AA5086 is clearly affected by both temperature and strain rate. At a low strain rate, the formability of AA5086 increases with the rising temperature, while at high strain rates (120 and $150 \mathrm{~s}^{-1}$ ), the limit strains at 230 and $290^{\circ} \mathrm{C}$ are clearly lower than that at room temperature. AA5086 is insensitive to strain rate at room temperature, while at elevated temperatures the limit strains at high strain rates are lower than that at low strain rate. Moreover, the limit strain does not decrease monotonically with increasing strain rate at elevated temperatures.

(2) A Lin-Voce constitutive model is proposed to describe the flow behavior of AA5086 under different temperatures and strain rates. The material parameters in the model have been identified by the inverse analysis and verified by uniaxial tensile test and Marciniak test.

(3) The FLCs of AA5086 at different temperatures (100, 200 and $\left.300^{\circ} \mathrm{C}\right)$ and strain rates $\left(2.5,120\right.$ and $\left.150 \mathrm{~s}^{-1}\right)$ are predicted by combining the Lin-Voce model with FE-Marciniak model. The effects of strain rate and temperature on FLCs are consistent with their effects on limit strains in the tensile tests. To improve the formability of AA5086 under high strain rates $\left(120\right.$ and $\left.150 \mathrm{~s}^{-1}\right)$, the blank must be heated to a certain temperature above $300^{\circ} \mathrm{C}$.

\section{Acknowledgement}

The authors would like to acknowledge financial support from National Natural Science Foundation of China (51105230, 51405266) and Encouragement Foundation for Young Scholars of Shandong Province (BS2010ZZ004).

\section{References:}

[1] Miller WS, Zhuang L, Bottema J, Wittebrood AJ, De Smet P, Haszler A, et al. Recent development in aluminium alloys for the automotive industry. Materials Science and Engineering: A. 2000, 280(1): 37-49.

[2] Heinz A, Haszler A, Keidel C, Moldenhauer S, Benedictus R, Miller WS. Recent development in 
aluminium alloys for aerospace applications. Materials Science and Engineering: A. 2000, 280(1): 102-107.

[3] Naka T, Yoshida F. Deep drawability of type 5083 aluminium-magnesium alloy sheet under various conditions of temperature and forming speed. Journal of Materials Processing Technology. 1999, 89: 19-23.

[4] Li D, Ghosh A. Tensile deformation behavior of aluminum alloys at warm forming temperatures. Materials Science and Engineering: A. 2003, 352(1): 279-286.

[5] Li DM, Ghosh AK. Effects of temperature and blank holding force on biaxial forming behavior of aluminum sheet alloys. Journal of Materials Engineering and Performance. 2004, 13(3): 348-360.

[6] Palumbo G, Tricarico L. Numerical and experimental investigations on the Warm Deep Drawing process of circular aluminum alloy specimens. Journal of Materials Processing Technology. 2007, 184(1): 115-123.

[7] Mahabunphachai S, Koc M. Investigations on forming of aluminum 5052 and 6061 sheet alloys at warm temperatures. Materials \& Design. 2010, 31(5): 2422-2434.

[8] Wang L, Strangwood M, Balint D, Lin J, Dean TA. Formability and failure mechanisms of AA2024 under hot forming conditions. Materials Science and Engineering: A. 2011, 528(6): 2648-2656.

[9] Fan X, He Z, Yuan S. Deformation behavior of 5A06 aluminum alloy sheet for rapid gas forming at elevated temperature. Transactions of Nonferrous Metals Society of China. 2012, 22: s389-s394.

[10] Wang H, Luo Y, Friedman P, Chen M, Gao L. Warm forming behavior of high strength aluminum alloy AA7075. Transactions of Nonferrous Metals Society of China. 2012, 22(1): 1-7.

[11] Keeler SP, Backofen WA. Plastic instability and fracture in sheets stretched over rigid punches. ASM Trans. Quart. 1963, 56(1): 25-48.

[12] Picu RC, Vincze G, Ozturk F, Gracio JJ, Barlat F, Maniatty AM. Strain rate sensitivity of the commercial aluminum alloy AA5182-O. Materials Science and Engineering: A. 2005, 390(1): 334-343.

[13] Abedrabbo N, Pourboghrat F, Carsley J. Forming of aluminum alloys at elevated temperatures Part 1: Material characterization. International Journal of Plasticity. 2006, 22(2): 314-341.

[14] Tarigopula V, Hopperstad OS, Langseth M, Clausen AH, Hild F. A study of localisation in dual-phase high-strength steels under dynamic loading using digital image correlation and FE analysis. International Journal of Solids and Structures. 2008, 45(2): 601-619.

[15] Naka T, Torikai G, Hino R, Yoshida F. The effects of temperature and forming speed on the forming limit diagram for type 5083 aluminum-magnesium alloy sheet. Journal of Materials Processing Technology. 2001, 113(1): 648-653.

[16] Chu X, Leotoing L, Guines D, Ragneau E. Temperature and strain rate influence on AA5086 Forming Limit Curves: Experimental results and discussion on the validity of the M-K model. International Journal of Mechanical Sciences. 2014, 78: 27-34.

[17] Khan AS, Baig M. Anisotropic responses, constitutive modeling and the effects of strain-rate and temperature on the formability of an aluminum alloy. International Journal of Plasticity. 2011, 27(4): 522-538.

[18] Zhang C, Leotoing L, Guines D, Ragneau E. Experimental and numerical study on effect of forming rate on AA5086 sheet formability. Materials Science and Engineering: A. 2010, 527(4): 967-972.

[19] Banabic D, Comsa S, Jurco P, Cosovici G, Paraianu L, Julean D. FLD theoretical model using a 
new anisotropic yield criterion. Journal of Materials Processing Technology. 2004, 157: 23-27.

[20] Zhang C, Leotoing L, Guines D, Ragneau E. Theoretical and numerical study of strain rate influence on AA5083 formability. Journal of Materials Processing Technology. 2009, 209(8): 3849-3858.

[21] Kim SB, Huh H, Bok HH, Moon MB. Forming limit diagram of auto-body steel sheets for high-speed sheet metal forming. Journal of Materials Processing Technology. 2011, 211(5): 851-862.

[22] Maier L. investigation of elongation at fracture in a high speed sheet metal forming process. Steel Research International. 2009, 80(5): 316-322.

[23] Sakai T, Watanabe Y, Utsunomiya H. Microstructure and texture of AZ80 magnesium alloy sheet rolled by high speed warm rolling. Materials Science Forum. 2009, 618: 483-486.

[24] Sanjari M, Farzadfar SA, Utsunomiya H, Sakai T, Essadiqi E, Yue S. High speed rolling of Mg-3Al-1Zn alloy: texture and microstructure analysis. Materials Science and Technology. 2012, 28(8): 928-933.

[25] Diot S, Guines D, Gavrus A, Ragneau E. Minimization of Friction Influence on the Evaluation of Rheological Parameters From Compression Test: Application to a Forging Steel Behavior Identification. Journal of Engineering Materials and Technology. 2009, 131(1): 011001.

[26] Aghaie-Khafri M, Mahmudi R. Predicting of plastic instability and forming limit diagrams. International Journal of Mechanical Sciences. 2004, 46(9): 1289-1306.

[27] Lee MG, Kim D, Kim CM, Wenner ML, Wagoner RH, Chung K. Spring-back evaluation of automotive sheets based on isotropic-kinematic hardening laws and non-quadratic anisotropic yield functions - Part II: characterization of material properties. International Journal of Plasticity. 2005,21:883-914.

[28] Aretz H. An extension of Hill's localized necking model. International Journal of Engineering Science. 2010, 48(3): 312-331.

[29] Abedrabbo N, Pourboghrat F, Carsley J. Forming of AA5182-O and AA5754-O at elevated temperatures using coupled thermo-mechanical finite element models. International Journal of Plasticity. 2007, 23(5): 841-875.

[30] Pedersen KO, Roven HJ, Lademo OG, Hopperstad OS. Strength and ductility of aluminium alloy AA7030. Materials Science and Engineering A. 2008, 473(1): 81-89.

[31] Rusinek A, Rodríguez-Martínez JA. Thermo-viscoplastic constitutive relation for aluminium alloys, modeling of negative strain rate sensitivity and viscous drag effects. Materials \& Design. 2009, 30(10): 4377-4390. 


\section{Table captions}

\section{Table 1}

Parameters identified for the modified Voce type hardening law.

\section{Table 2}

Yield strength of AA5086 identified at different temperatures.

\section{Table 3}

Identified parameters in Lin-Voce constitutive model by the inverse analysis.

\section{Table 4}

Comparison of major strains at different temperatures.

\section{Table 5}

Parameters obtained for the yield strength equation.

\section{Table 6}

Comparison of limit strains at room temperature and at $350^{\circ} \mathrm{C}$. 


\section{Table 1}

Parameters identified for the modified Voce type hardening law.

\begin{tabular}{cccccc}
\hline Temperature $/{ }^{\circ} \mathrm{C}$ & $C_{1}$ & $C_{2}$ & $C_{3}$ & $C_{4}$ & Error \\
\hline 20 & 88.05 & 2.01 & $2.18 \mathrm{E}-04$ & 437.19 & $0.97 \%$ \\
230 & 80.0 & 2.92 & $1.10 \mathrm{E}-04$ & 350.0 & $1.32 \%$ \\
290 & 64.0 & 3.50 & $2.90 \mathrm{E}-04$ & 340.0 & $2.62 \%$ \\
\hline
\end{tabular}

Table 2

Yield strength of AA5086 identified at different temperatures.

\begin{tabular}{cc}
\hline Temperature $/{ }^{\circ} \mathrm{C}$ & Yield strength/MPa \\
\hline 20 & 134.81 \\
230 & 133.43 \\
290 & 125.51 \\
\hline
\end{tabular}




\section{Table 3}

Identified parameters in Lin-Voce constitutive model by the inverse analysis.

\begin{tabular}{ccccccc}
\hline Strain rate/ s & $C_{1}$ & $C_{2}$ & $C_{3}$ & $C_{4}$ & $C_{5}$ & Error \\
\hline 2.5 & 756.26 & -1.0387 & 1.5508 & 0.00974 & 0.00003868 & $1.86 \%$ \\
120 & 726.88 & -0.8693 & 1.2932 & 0.00317 & 0.00003166 & $2.66 \%$ \\
150 & 698.83 & -0.8392 & 1.5714 & 0.01038 & 0.00002545 & $2.48 \%$ \\
\hline
\end{tabular}

\section{Table 4}

Comparison of major strains at different temperatures.

\begin{tabular}{ccccc}
\hline \multirow{2}{*}{ Strain rate/ s } & \multicolumn{4}{c}{ Major strain } \\
& $180^{\circ} \mathrm{C}$ & $230^{\circ} \mathrm{C}$ & $\mathbf{2 5 0}{ }^{\circ} \mathrm{C}$ & $260^{\circ} \mathrm{C}$ \\
\hline 120 & 0.229 & 0.211 & $\mathbf{0 . 2 0 8}$ & 0.23 \\
150 & 0.24 & 0.227 & $\mathbf{0 . 2 2 3}$ & 0.245 \\
\hline
\end{tabular}


Table 5

Parameters obtained for the yield strength equation.

\begin{tabular}{cccc}
\hline$k_{1}$ & $k_{2}$ & $T_{m} / K$ & $T_{0} / K$ \\
\hline 0.1043 & 2.7028 & 900 & 273 \\
\hline
\end{tabular}

\section{Table 6}

Comparison of limit strains at room temperature and at $350^{\circ} \mathrm{C}$.

\begin{tabular}{lccccc}
\hline Strain state & $\begin{array}{c}\text { Major strain } \\
\left(20^{\circ} \mathrm{C}\right)\end{array}$ & Major strain & Increasing rate & Major strain & Increasing rate \\
\hline Uniaxial tension & 0.37 & 0.39 & $5.41 \%$ & 0.42 & $13.51 \%$ \\
Plane strain & 0.22 & 0.26 & $18.18 \%$ & 0.29 & $31.82 \%$ \\
$\begin{array}{l}\text { Equi-biaxial } \\
\text { stretching }\end{array}$ & 0.38 & 0.45 & $18.42 \%$ & 0.47 & $23.68 \%$ \\
\hline
\end{tabular}




\section{Figure captions}

Fig. 1. Notched tensile specimen and grip system (unit: $\mathrm{mm}$ ).

Fig. 2. Force vs time curves for different temperatures at a given strain rate.
(a) $2.5 \mathrm{~s}^{-1}$
(b) $120 \mathrm{~s}^{-1}$
(c) $150 \mathrm{~s}^{-1}$

Fig. 3. Force vs displacement curves for different strain rates at a given temperature.
(a) $20^{\circ} \mathrm{C}$
(b) $290^{\circ} \mathrm{C}$

Fig. 4. Limit strains at different temperatures and strain rates.

Fig. 5. Principal of the optimization procedure by the inverse analysis.

Fig. 6. FE model of the tensile test used for the inverse analysis.

Fig. 7. Linear relationship between strain hardening parameters and temperature.

Fig. 8. Comparison of experimental and identified force vs time curves by Lin-Voce model.
(a) $2.5 \mathrm{~s}^{-1}$
(b) $120 \mathrm{~s}^{-1}$
(c) $150 \mathrm{~s}^{-1}$

Fig. 9. Experimental and numerical limit strains at different strain rates and temperatures.

Fig. 10. Marciniak test setup and its schematic illustration.

Fig. 11. Specimens used in Marciniak test.

Fig. 12. Illustration of FE-Marciniak model.

Fig. 13. Comparison of FLCs obtained by the physical Marciniak test and FE simulation.

Fig. 14. Yield strengths at different temperatures and its fitting curve.

Fig. 15. Comparison of FLCs for different temperatures at a given strain rate
(a) $2.5 \mathrm{~s}^{-1}$
(b) $120 \mathrm{~s}^{-1}$
(c) $150 \mathrm{~s}^{-1}$

Fig. 16. Comparison of FLCs under different strain rates at a given temperature.
(a) $100^{\circ} \mathrm{C}$
(b) $200^{\circ} \mathrm{C}$
(c) $300^{\circ} \mathrm{C}$ 

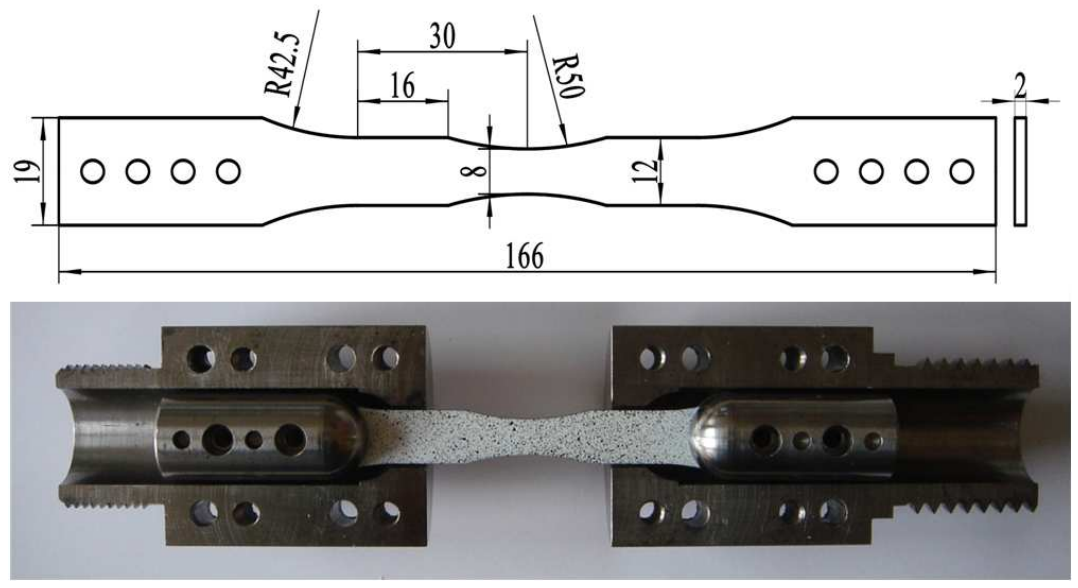

Fig. 1. Notched tensile specimen and grip system (unit: mm).

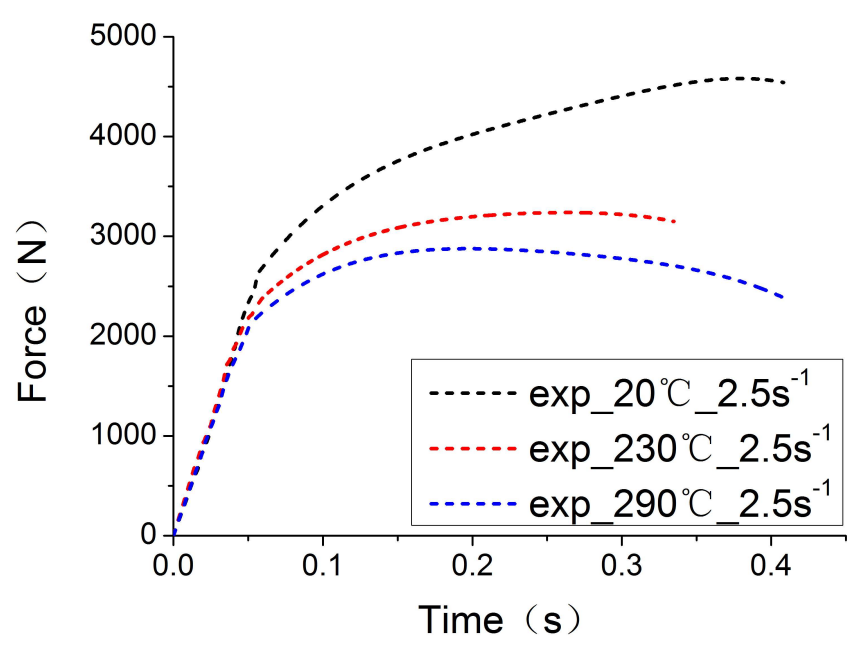

(a) $2.5 \mathrm{~s}^{-1}$

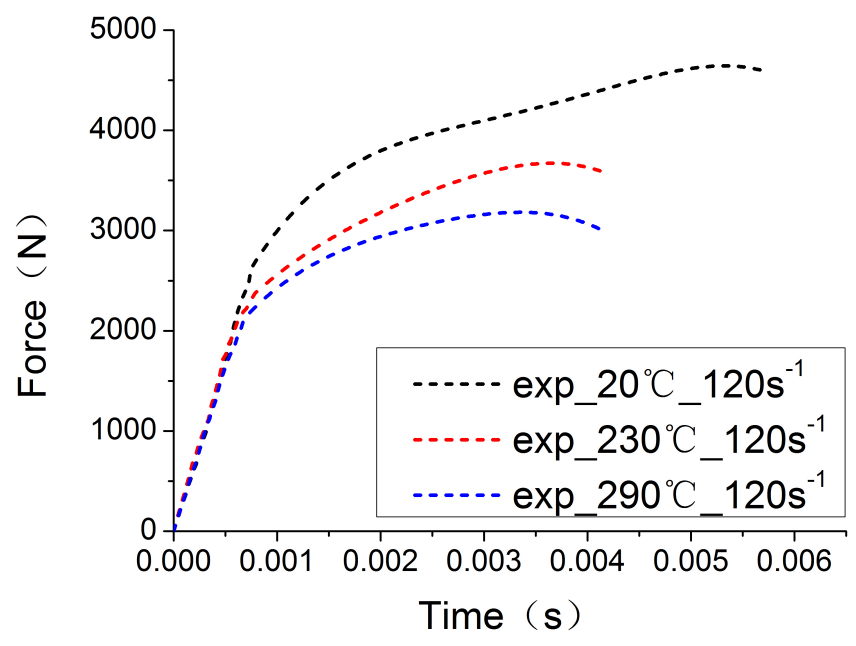

(b) $120 \mathrm{~s}^{-1}$ 


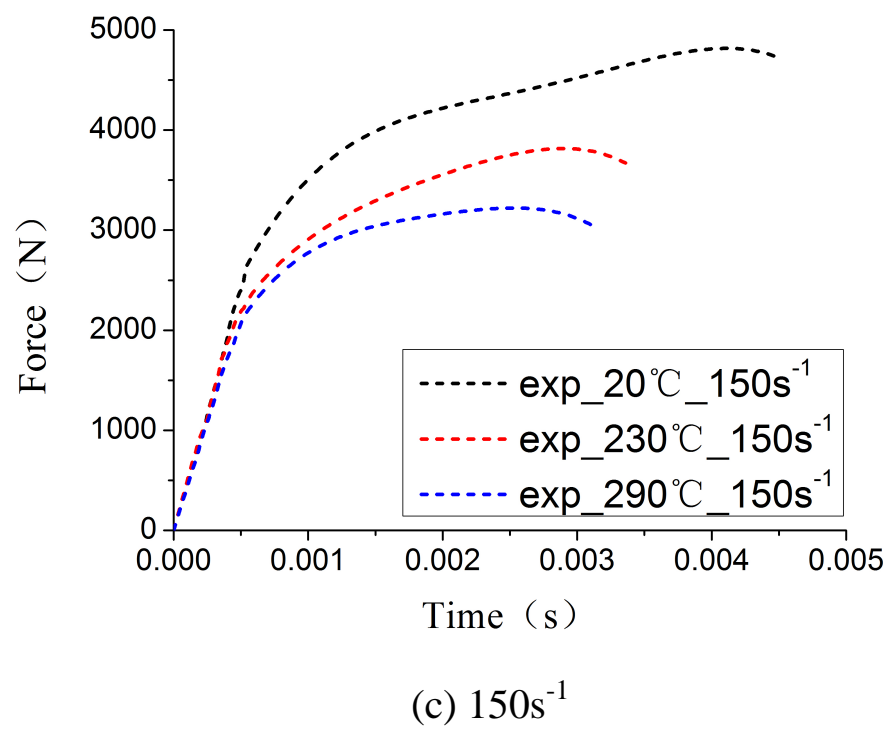

Fig. 2. Force vs time curves for different temperatures at a given strain rate.

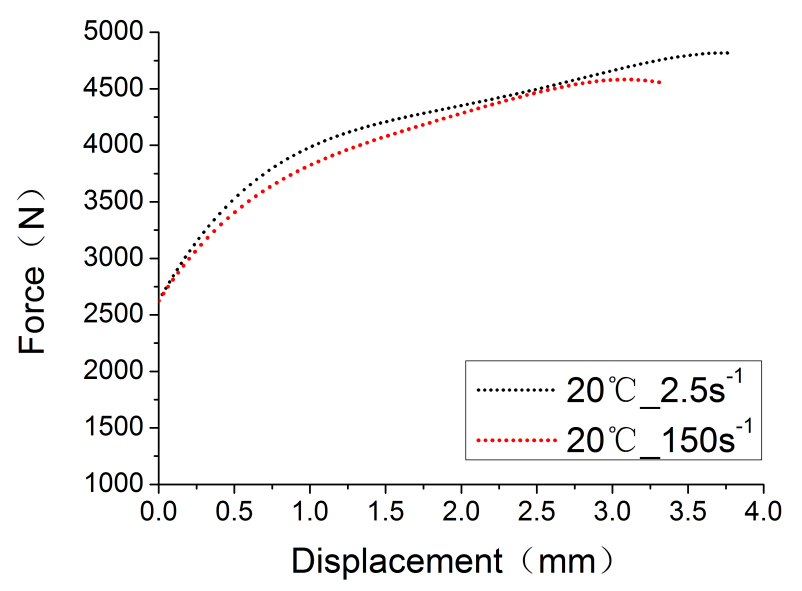

(a) $20^{\circ} \mathrm{C}$

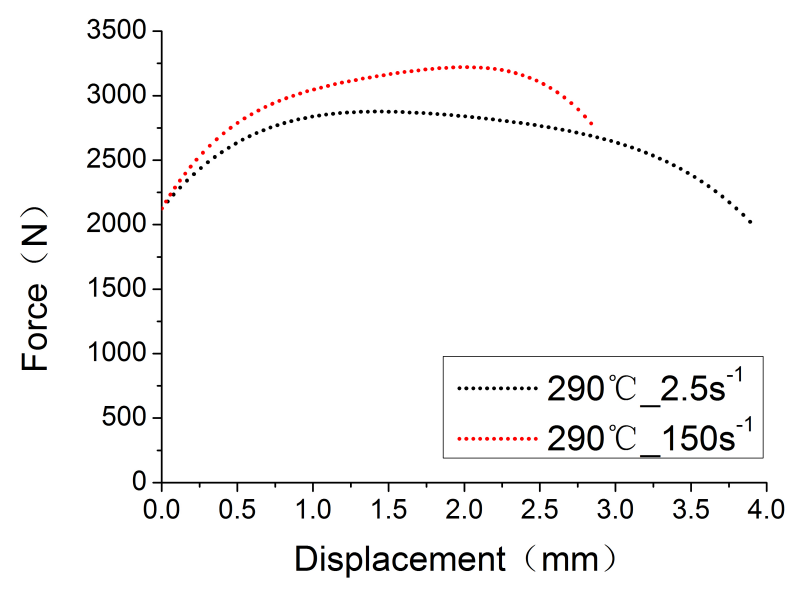

(b) $290^{\circ} \mathrm{C}$ 
Fig. 3. Force vs displacement curves for different strain rates at a given temperature.

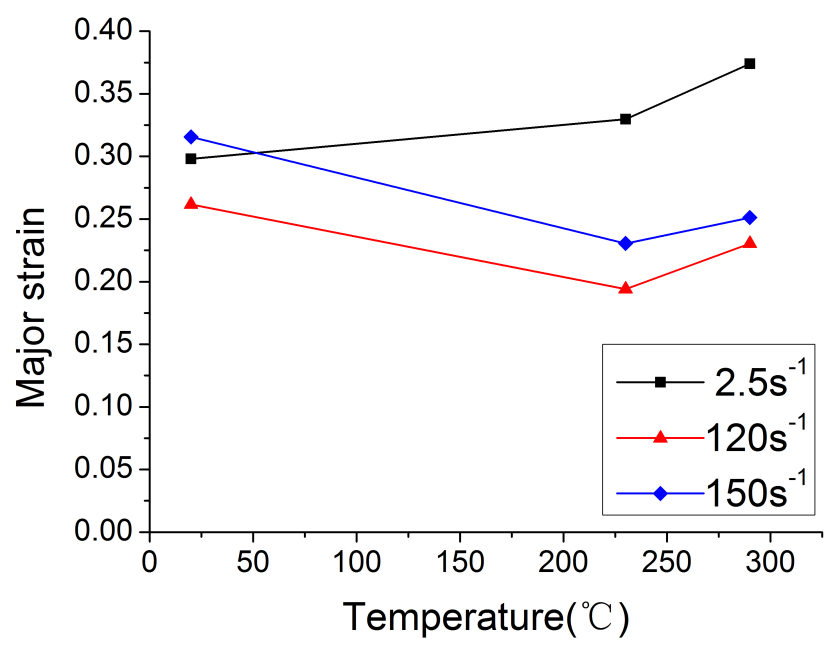

Fig. 4. Limit strains at different temperatures and strain rates.

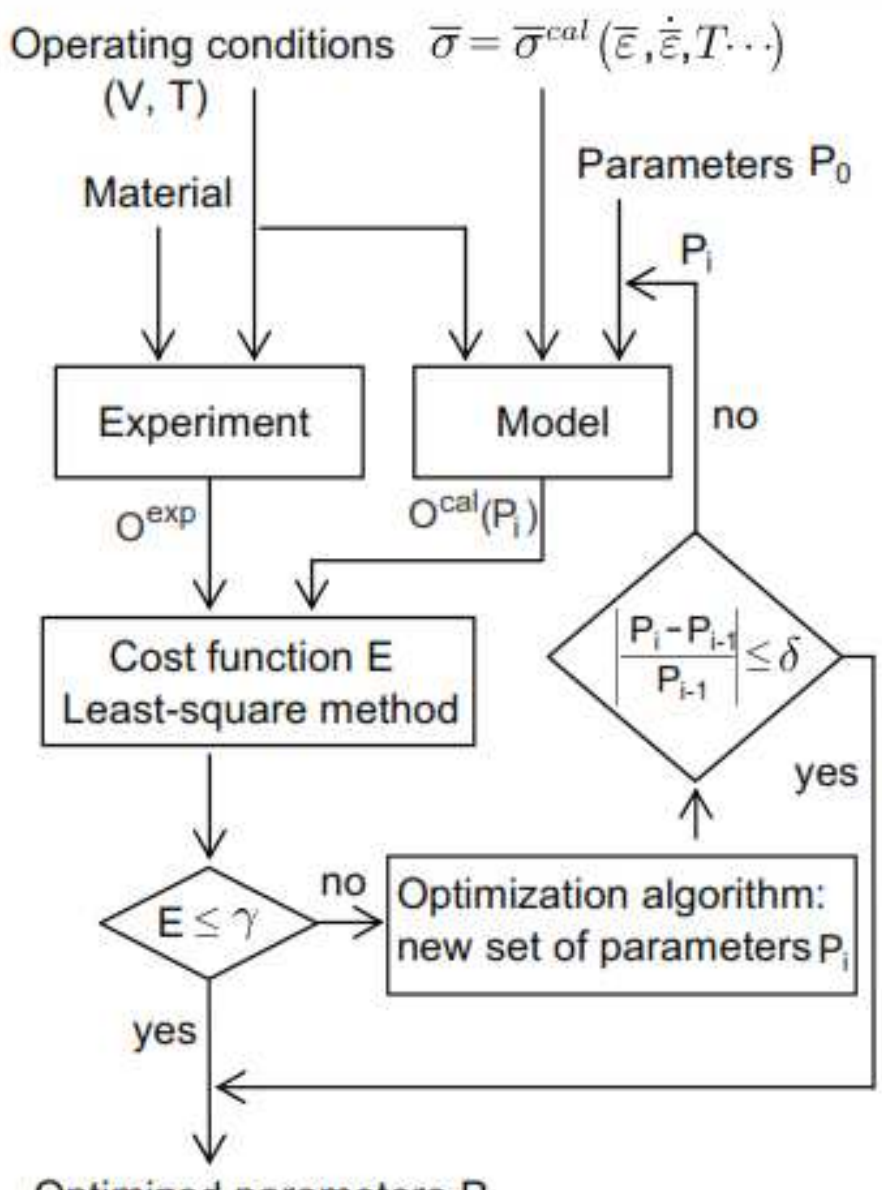

Optimized parameters $\mathrm{P}$

Fig. 5. Principal of the optimization procedure by the inverse analysis. 


\section{Specimen}

\section{Truss}

Fig. 6. FE model of the tensile test used for the inverse analysis.

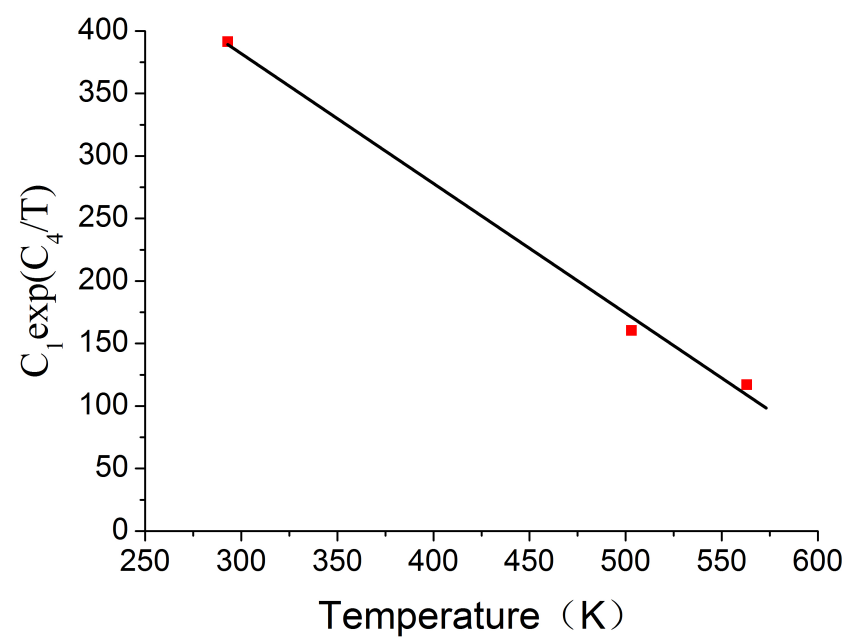

Fig. 7. Linear relationship between strain hardening parameters and temperature.

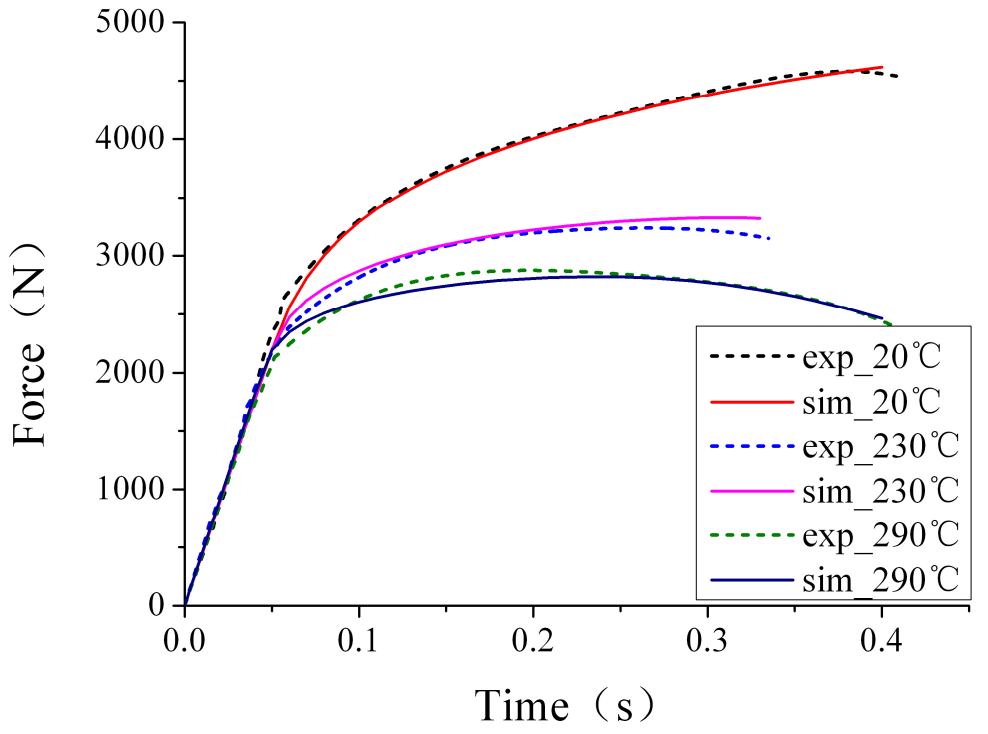

(a) $2.5 \mathrm{~s}^{-1}$ 


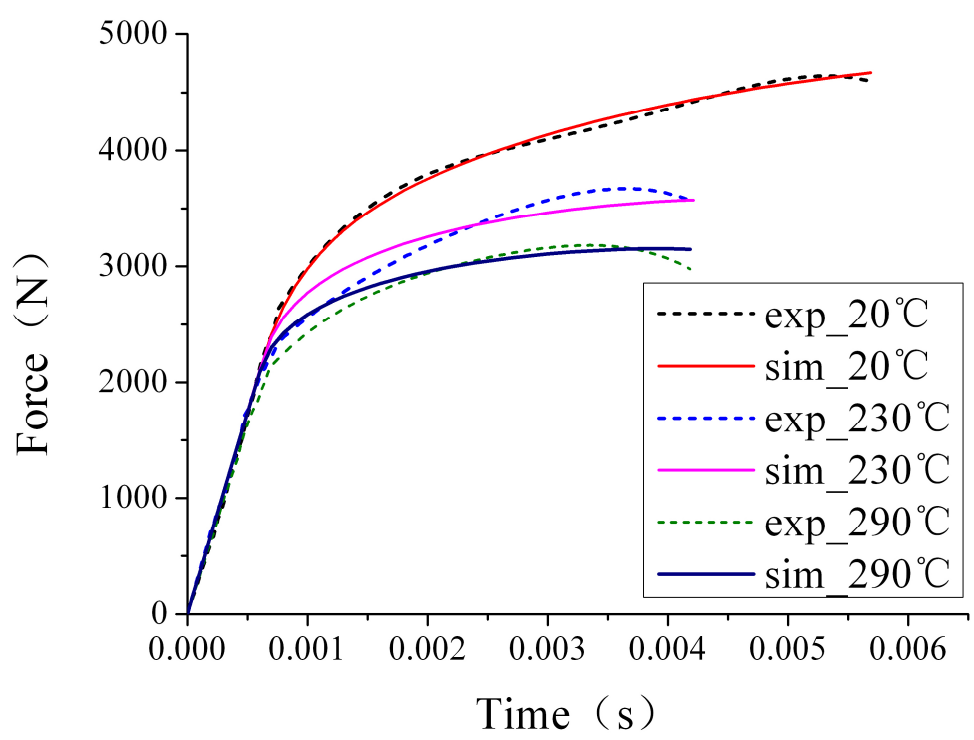

(b) $120 \mathrm{~s}^{-1}$

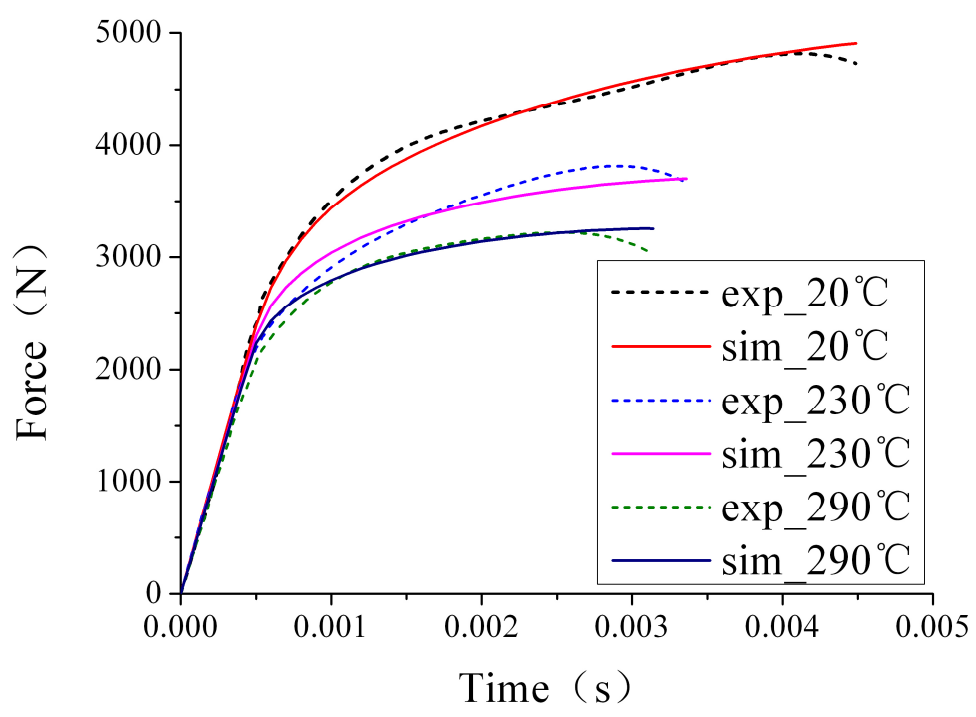

(c) $150 \mathrm{~s}^{-1}$

Fig. 8. Comparison of experimental and identified force vs time curves by Lin-Voce model. 


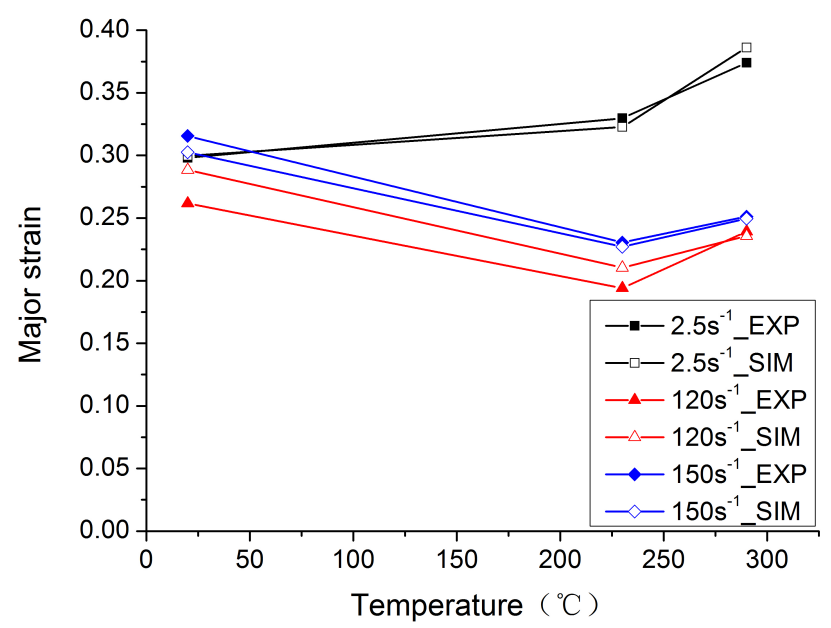

Fig. 9. Experimental and numerical limit strains at different strain rates and temperatures.
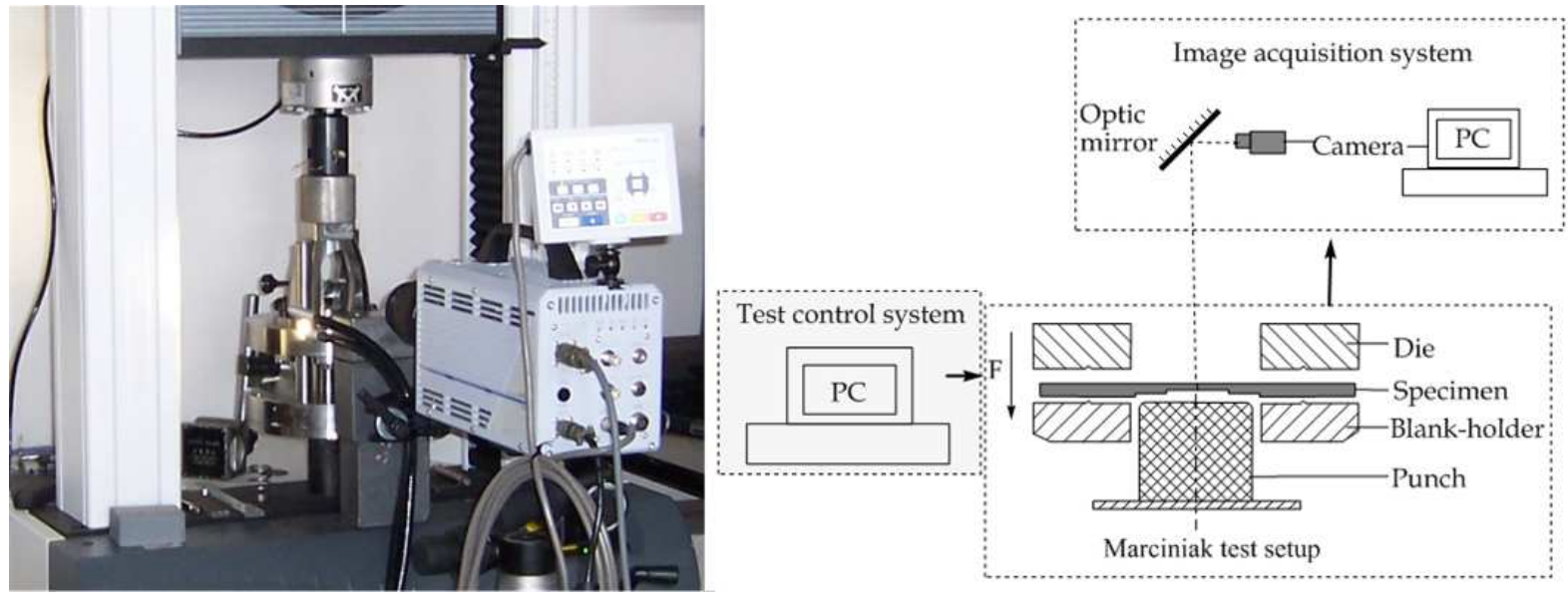

Fig. 10. Marciniak test setup and its schematic illustration.

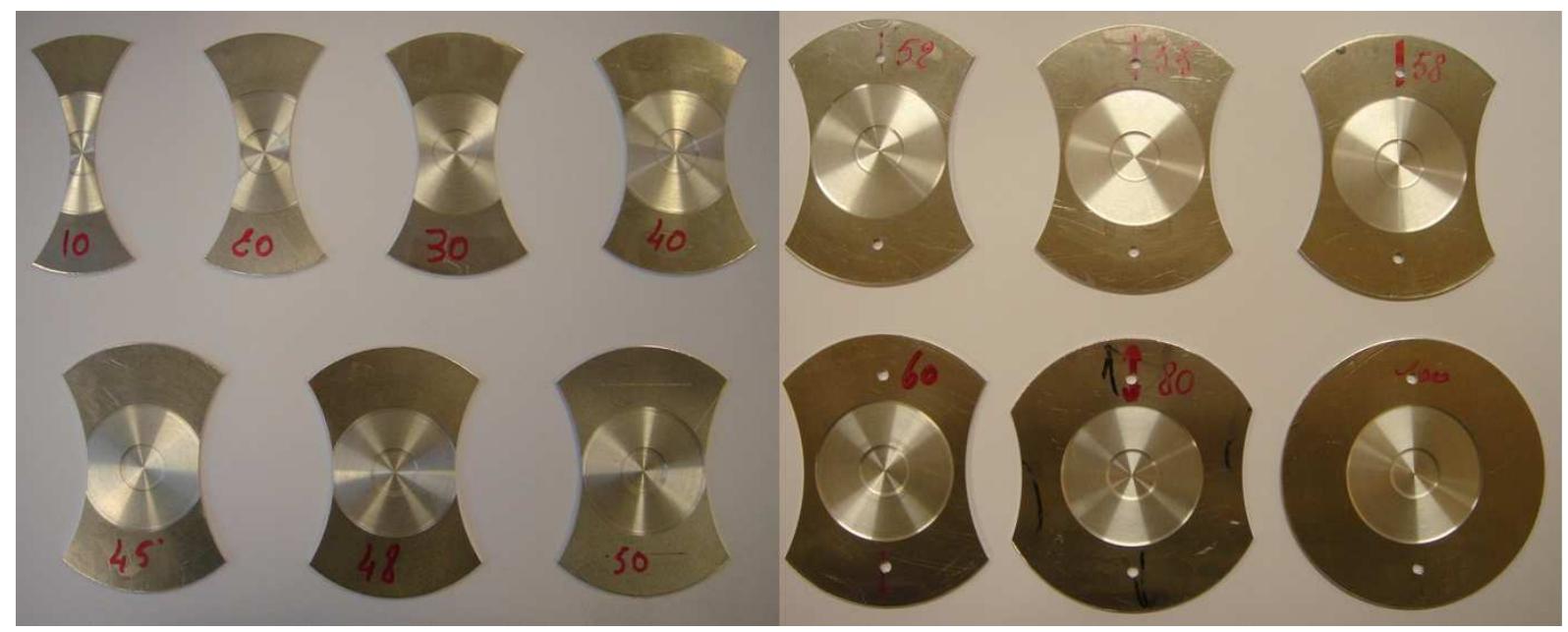

Fig. 11. Specimens used in Marciniak test. 


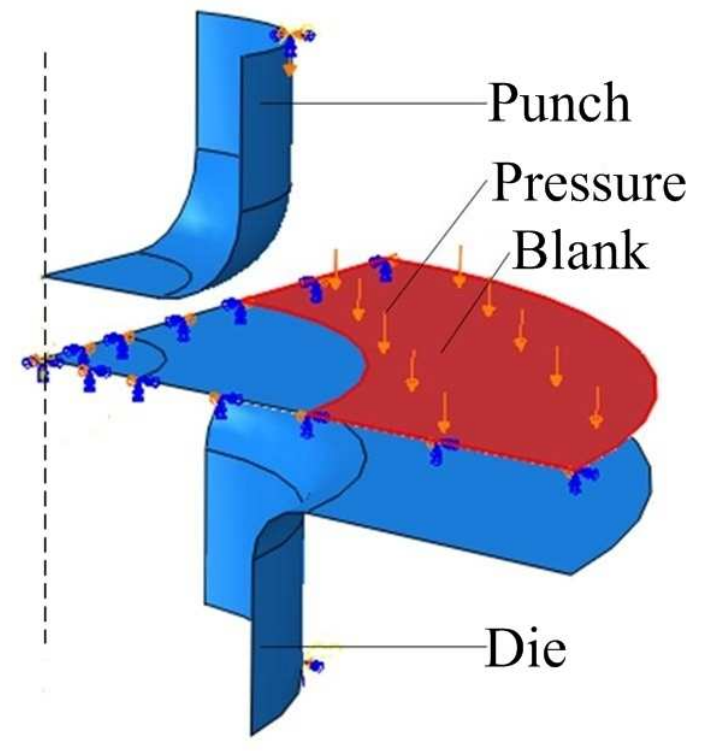

Fig. 12. Illustration of FE-Marciniak model.

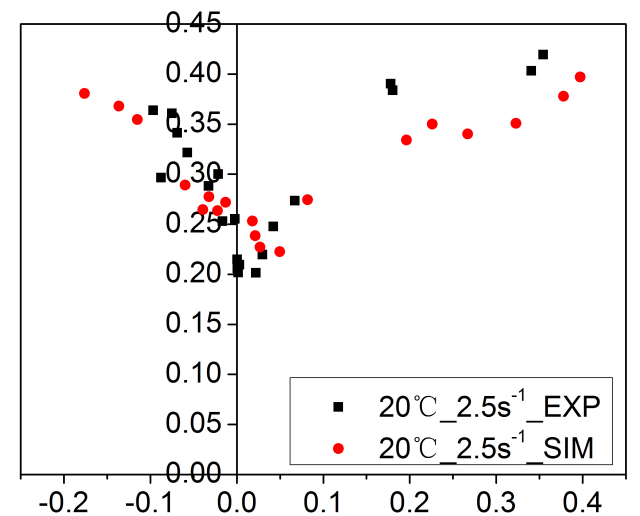

Fig. 13. Comparison of FLCs obtained by the physical Marciniak test and FE simulation.

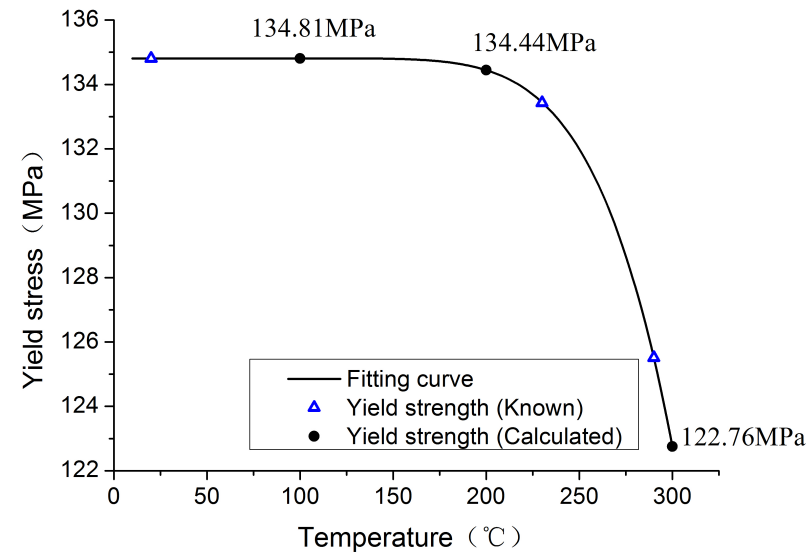

Fig. 14. Yield strengths at different temperatures and its fitting curve. 


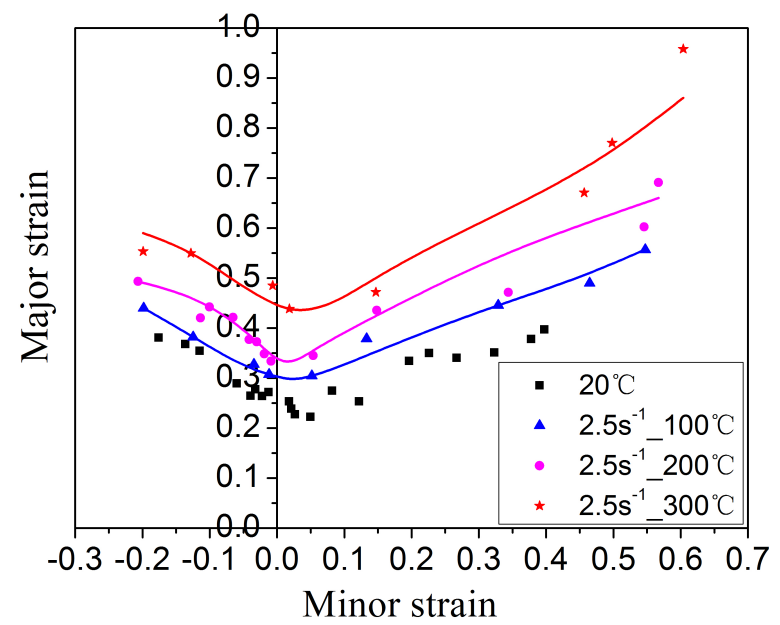

(a) $2.5 \mathrm{~s}^{-1}$

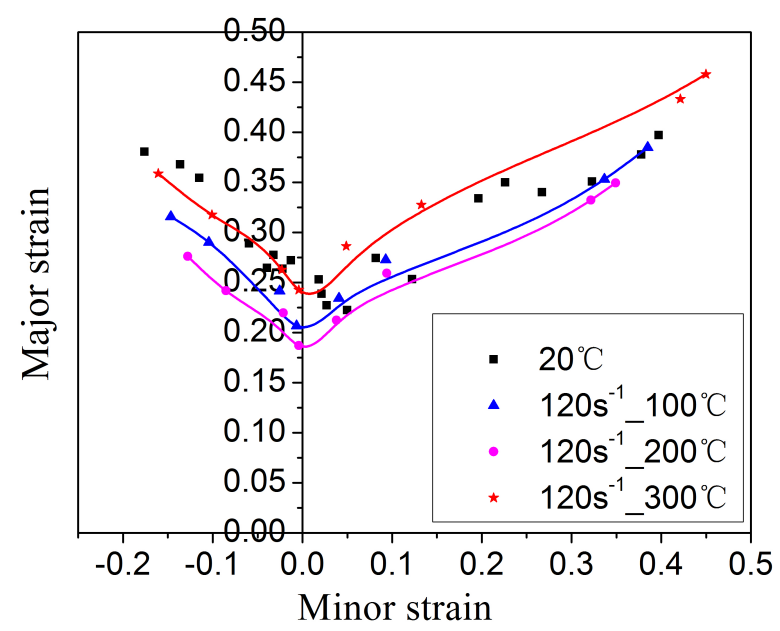

(b) $120 \mathrm{~s}^{-1}$

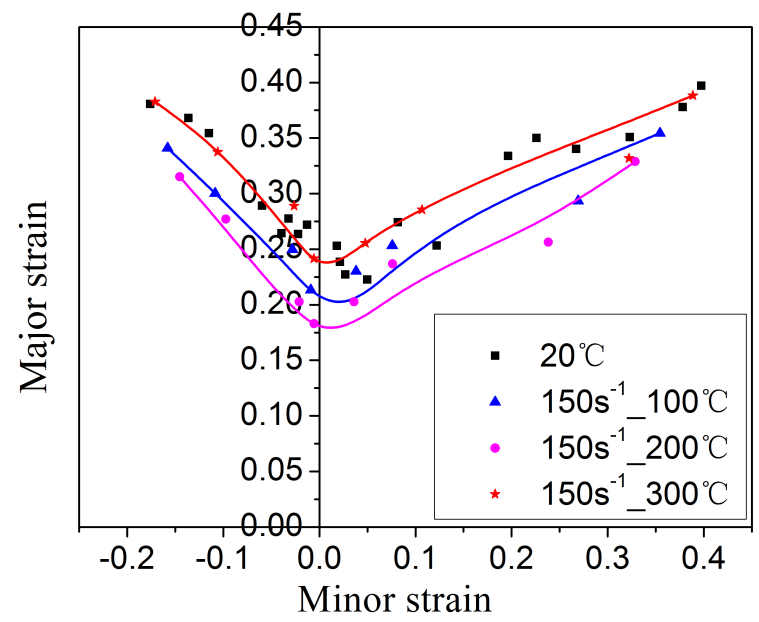

(c) $150 \mathrm{~s}^{-1}$

Fig. 15. Comparison of FLCs for different temperatures at a given strain rate 


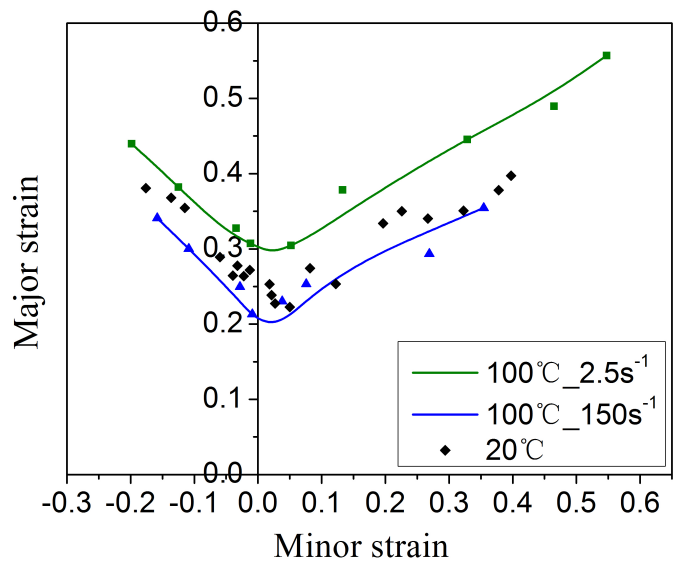

(a) $100^{\circ} \mathrm{C}$

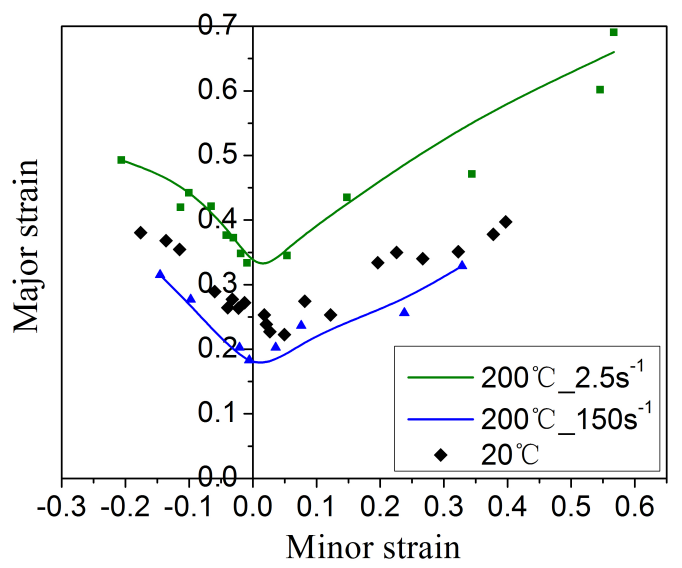

(b) $200^{\circ} \mathrm{C}$

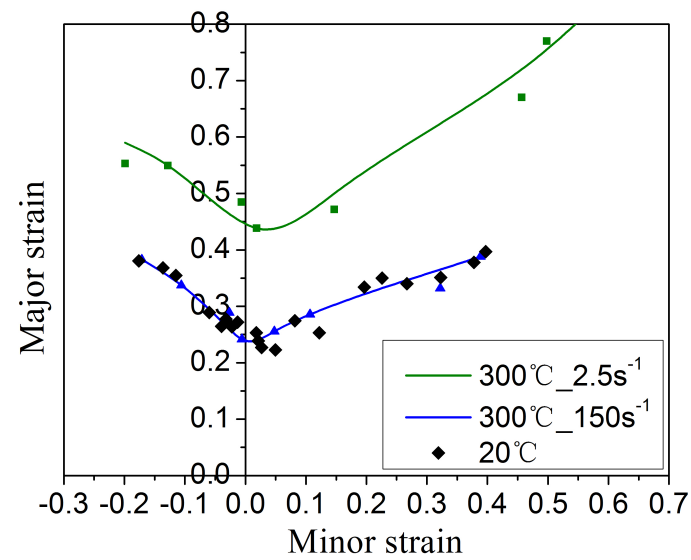

(c) $300^{\circ} \mathrm{C}$

Fig. 16. Comparison of FLCs under different strain rates at a given temperature. 